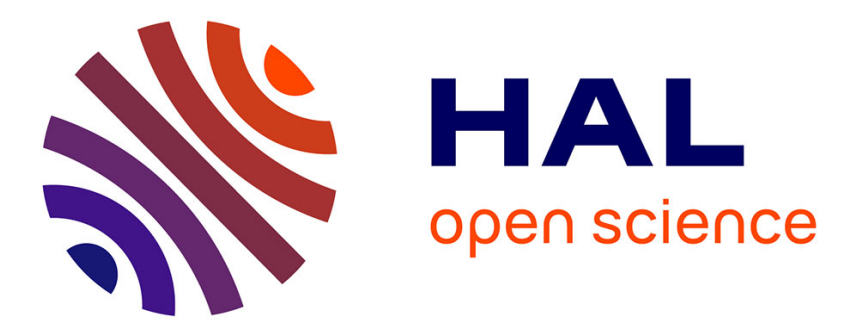

\title{
Modelling the spatial configuration of refuges for a sustainable control of pests: a case study of Bt cotton
}

Corinne Vacher, Denis D. Bourguet, François Rousset, Christine Chevillon, Michael Hochberg

\section{- To cite this version:}

Corinne Vacher, Denis D. Bourguet, François Rousset, Christine Chevillon, Michael Hochberg. Modelling the spatial configuration of refuges for a sustainable control of pests: a case study of Bt cotton. Journal of Evolutionary Biology, 2003, 16 (3), pp.378-387. 10.1046/j.1420-9101.2003.00553.x . hal02674164

\section{HAL Id: hal-02674164 \\ https://hal.inrae.fr/hal-02674164}

Submitted on 12 Aug 2020

HAL is a multi-disciplinary open access archive for the deposit and dissemination of scientific research documents, whether they are published or not. The documents may come from teaching and research institutions in France or abroad, or from public or private research centers.
L'archive ouverte pluridisciplinaire HAL, est destinée au dépôt et à la diffusion de documents scientifiques de niveau recherche, publiés ou non, émanant des établissements d'enseignement et de recherche français ou étrangers, des laboratoires publics ou privés. 


\title{
Modelling the spatial configuration of refuges for a sustainable control of pests: a case study of Bt cotton
}

\author{
C. VACHER, ${ }^{\star}$ D. BOURGUET, $\dagger$ F. ROUSSET, ${ }^{*}$ C. CHEVILLON* \& M. E. HOCHBERG* \\ * Laboratoire Génétique et Environnement, Institut des Sciences de l'Evolution, Université Montpellier II, Montpellier Cedex, France \\ $\dagger$ †nité de Recherches de Lutte Biologique, Institut National de la Recherche Agronomique La Minière, Guyancourt, France
}

Keywords:

cotton;

Heliothis virescens;

refuges;

resistance management:

spatial model;

sustainable pest control;

transgenic crops.

\begin{abstract}
The 'high-dose-refuge' (HDR) strategy is widely recommended by the biotechnology industry and regulatory authorities to delay pest adaptation to transgenic crops that produce Bacillus thuringiensis (Bt) toxins. This involves cultivating nontoxic plants (refuges) in close proximity to crops producing a high dose of $B t$ toxin. The principal cost associated with this strategy is due to yield losses suffered by farmers growing unprotected, refuge plants. Using a population genetic model of selection in a spatially heterogeneous environment, we show the existence of an optimal spatial configuration of refuges that could prevent the evolution of resistance whilst reducing the use of costly refuges. In particular, the sustainable control of pests is achievable with the use of more aggregated distributions of nontransgenic plants and transgenic plants producing lower doses of toxin. The HDR strategy is thus suboptimal within the context of sustainable agricultural development.
\end{abstract}

\section{Introduction}

Economic realities will determine the success of transgenic crops that produce Bacillus thuringiensis (Bt) and, because their development costs are much greater than those of conventional crops, their widespread use will depend on them having a reasonably long effective lifetime (Rausher, 2000). Limiting pest adaptation to Bt toxin is therefore a major goal of the biotechnology industry. Beyond profits made by the biotechnology industry in cases of long-term success of $B t$ crops, the widespread use of these crops may also reduce the application of chemical pesticides and have positive effects on the environment, in particular, decreasing soil and water pollution (Gianessi \& Carpenter, 1999; Wolfenbarger \& Phifer, 2000). Rapid pest adaptation to $B t$ toxins would compromise these positive impacts of $B t$ crops, without altering their main environmental risks (see Daniels \& Sheail, 1999; Wolfenbarger \& Phifer, 2000).

Correspondence: Michael E. Hochberg, Laboratoire Génétique et Environnement, Institut des Sciences de l'Evolution (UMR5554), Université Montpellier II, 34095 Montpellier Cedex 5, France. Tel./fax: +33 467 143667; e-mail: hochberg@isem.univ-montp2.fr
Limiting pest adaptation to the $B t$ toxin is therefore also of concern to environmental protection organizations.

The resistance management strategy most commonly used since 1991, when Monsanto (St Louis, MO, USA) scientists produced plants with toxin titres high enough to kill $100 \%$ of susceptible target insect genotypes, is the 'high-dose-refuge' (HDR) strategy. Other strategies, such as the 'low-dose' strategy coupled with biological control, or the tissue-, time- or signal-dependent expression of toxin genes, have received very little attention (Gould, 1998). Refuges are defined as non-Bt plants that can be used by the target pest and that are planted and maintained in close proximity to Bt crops (Gould, 1998). Under $H D R, 100 \%$ of the susceptible homozygotes and the vast majority of heterozygotes die following the consumption of Bt plants. The few surviving heterozygotes are subsequently more likely to mate with susceptible homozygotes produced by non-Bt refuge plants, preventing the emergence of resistant homozygotes (Gould, 1998). The efficiency (Bourguet et al., 2000a; Carrière $\&$ Tabashnik, 2001) of HDR depends on the initial rarity of the resistance allele, resistance being functionally recessive, and random or preferential mating between resistant and susceptible genotypes. 
Computer simulations have shown that HDR may delay the evolution of resistance by several years (e.g. Mallet \& Porter, 1992; Tabashnik, 1994; Caprio, 1998; Onstad \& Gould, 1998). However, in the real world, many ecological and genetic features of pests may limit the efficiency of the HDR strategy (Gould, 1998). Moreover, models of resistance evolution often present two limiting simplifications. Firstly, they generally ignore the spatial distributions of crops and migrating pests (but see Lenormand \& Raymond, 1998; Peck et al., 1999; Caprio, 2001). The only clear conclusion that can be drawn concerning the impact of the spatial structure of the agrosystem is that cultivating non-Bt plants in separate areas is more efficient at curbing the evolution of resistance than is growing resistant and susceptible plants in the same field (Mallet \& Porter, 1992; Tabashnik, 1994; Onstad \& Gould, 1998). Experimental studies have recently provided additional support for this conclusion (Shelton et al., 2000; Tang et al., 2001). Thus, it seems that transgenic and nontransgenic plants should be grown in separate fields. To our knowledge, no study has addressed the question of how separate refuge fields should be distributed amongst transgenic fields. However, the United States Environmental Protection Agency (USEPA) guidelines on this issue are explicit: in the case of untreated corn external refugia must be within half a mile of the Bt field; growers may also choose to plant refugia as strips within a $B t$ field, with strips being arranged in alternative increments of six rows each (Andersen, 1999; Neppl, 2000).

Secondly, models of resistance evolution generally assume that resistance to $B t$ toxin does not entail a cost (Mallet \& Porter, 1992; Tabashnik, 1994; Alstad \& Andow, 1995; Ives, 1996; Caprio, 1998; Roush, 1998; Peck et al., 1999). Indeed, fitness costs associated with resistance are difficult to detect and their existence is a matter of debate (Cousteau et al., 2000). However, costs have been experimentally shown for chemical pesticide resistance in the mosquito Culex pipiens (Raymond et al., 1998), and the fly Lucilia cuprina (McKenzie \& Purvis, 1984), and they are thought to be involved in the reduced fitness of Plutella xylostella and Leptinotarsa decemnileata strains resistant to Bt crops (Groeters et al., 1994; Alyokhin \& Ferro, 1999a). The existence of a resistance cost would result in selection against resistance in refuge fields and, consequently, an optimal arrangement of refuge and transgenic fields could create a selective regime that, on balance, acts against resistance. This contrasts strongly with management strategies based on the no-cost assumption: in the assumed absence of counter-selection, these strategies are designed simply to delay the fixation of resistance alleles (e.g. Mallet \& Porter, 1992; Tabashnik, 1994; Caprio, 1998, 2001; Onstad \& Gould, 1998). We study cases in which there is a cost to resistance, and therefore the possibility of preventing the evolution of resistance (see also Lenormand \& Raymond, 1998; Carrière \& Tabashnik, 2001).

Carrière $\delta$ Tabashnik (2001) recently pointed out that, in addition to high costs of resistance, large refuges are necessary to prevent or reverse resistance evolution in pests. However, farmers are unlikely to accept the idea of large refuges because they constitute unprotected areas, representing short-term economic losses (ILSI, 1998). Here, we develop and analyse a resistance management model aimed at preventing the evolution of resistance whilst reducing the use of costly refuges. We focus on one well-known crop/pest system - Bt cotton and one of its major pests, Heliothis virescens - in order to address the following issues with biologically realistic information: (1) What is the optimal percentage and spatial configuration of refuge fields for a sustainable pest control? (2) What is the impact of the toxin dose produced by transgenic plants on this optimal strategy? and (3) What is the robustness of this optimal strategy towards features of the biological system?

\section{Methods}

\section{Model habitat}

The model habitat is a $n \times n$ grid of toxic and refuge fields $(n=20)$. The distance $d$ between adjacent fields is set at $2 \mathrm{~km}$. All the fields are of equal size and a percentage $P_{\text {ref }}$ of fields are used as refuges. We explored a range of refuge distributions, including uniform, random and aggregated distributions into strips (Fig. 1). The level of aggregation, $A_{g}$, corresponds to the number of strips $\left(1 \leq A_{g} \leq 5\right)$.

\section{Pest genetics}

Resistance is determined by a single diallelic locus $(R$ : resistance; $S$ : susceptibility). Genotypic fitness can be

Fig. 1 Examples of refuge distributions employed in our study: (a) uniform, (b) random, (c) aggregated into four strips, (d) aggregated into two strips. The percentage of refuge $\left(P_{\text {ref }}\right)$ equals $20 \%$. Refuge fields are indicated in black and transgenic fields are indicated in white.

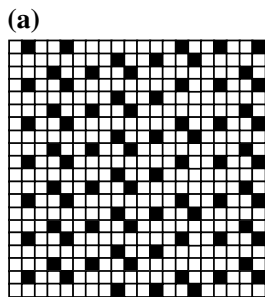

(b)

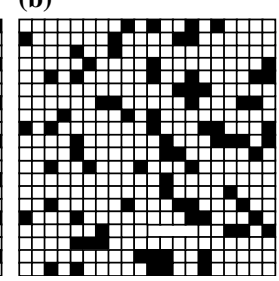

(c)

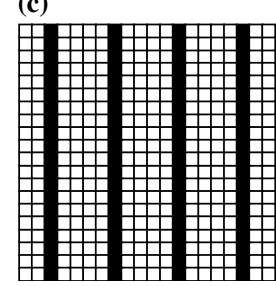

(d)

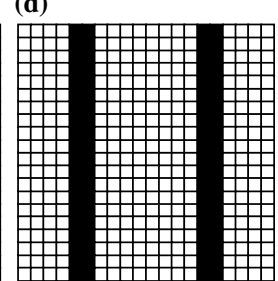


expressed as (Lenormand \& Raymond, 1998; Bourguet et al., 2000b):

$$
\begin{gathered}
W_{\mathrm{RR}}=1-c \\
W_{\mathrm{RS}}=1-h_{\mathrm{c}} c-h_{\mathrm{S}} s g(x) \\
W_{\mathrm{SS}}=1-s g(x)
\end{gathered}
$$

where $s$ is the selection coefficient in the presence of $B t$ toxin and $c$ is the fitness cost of resistance. The coefficient $h_{s}$ is the dominance level associated with toxin selection in transgenic Bt plants. The coefficient $h_{c}$, which corresponds to the definition of $D_{W N T}$ given in Bourguet et al. $(2000 \mathrm{~b})$, is the dominance level of the fitness cost. The function $g(x)$ is one if field $x$ is planted with transgenic plants; otherwise, it is zero.

\section{Pest life cycle}

The model also assumes that reproduction precedes selection, which, in turn, precedes migration (Fig. 2). Reproduction is assumed to be panmictic at the field scale. After reproduction, fields are re-saturated to carrying capacity and carrying capacities are assumed to be equal in transgenic and refuge fields. Indeed, as agricultural pests usually have very high levels of fecundity (Gianessi \& Carpenter, 1999), it can be assumed that immigrant females and the few emerging resistant females lay enough eggs in transgenic fields to reach a larval density close to the carrying capacity. Migration distances follow a bivariate Gaussian distribution, with variance $\sigma^{2}$. The distribution $M$ of imagos from the same field is calculated by projecting migration trajectories on two axes, $x$ and $y$, parallel to the grid border. As the spatial system is discrete, a Gaussian distribution of migration distances on each axis, $P$, is approximated by a symmetric binomial distribution $B(2 t, 1 / 2)$ :

$$
P(P=i)=C(2 t, i+t)(1 / 2)^{t+i}(1 / 2)^{t-i}
$$

The variance of the distribution $\sigma^{2}$ is $d^{2} t / 2$ (Lenormand $\delta$ Raymond, 1998). The probability that an imago migrates towards field $m$ is defined as the product of the probabilities of projected distances $m_{x}$ and $m_{y}$ on each axis:

$$
P(M=m)=P\left(P=m_{\mathrm{x}}\right) \times P\left(P=m_{\mathrm{y}}\right)
$$

Grid borders are assumed to be reflective boundaries. Consequently, migration does not modify total pest number.

\section{Model parameters}

The model parameters employed in this study are based on the tobacco budworm Heliothis virescens (Lepidoptera: Noctuidae), a key pest of cotton crops. The standard error $\sigma^{2}$ of migration is estimated as $4 \mathrm{~km}$ (Korman et al., 1993). The initial frequency of the resistance allele $f_{s o}$ is assumed to be 0.0015 (Gould et al., 1997). The varieties of Bt cotton currently available are highly toxic to tobacco budworm larvae (Gianessi \& Carpenter, 1999) and the recent determination of the molecular basis of BtCryl Ac resistance (Gahan et al., 2001) is consistent with resistance being recessive, as observed in bioassays (Gould et al., 1995). A 'high dose' strategy, killing more than $97 \%$ of heterozygotes and susceptible homozygotes ( $s=1.00$ and $\left.h_{s}=0.95\right)$ is used in most simulations. We also studied a 'middle dose' strategy $(s=0.80)$ and a 'low dose' strategy $(s=0.60)$. We assumed that the genotype toxin dose-mortality curves for insect larvae are such that the functional recessivity of resistance $\left(h_{s}\right)$ is not affected by the amount of toxin produced by transgenic plants. An acute, recessive cost of resistance has already been observed in the laboratory for some strains of $H$. virescens (F. Gould, personal communication). In the absence of quantitative data, for the main simulations we fixed the cost of resistance $c$ to 0.15 and its level of dominance $h_{c}$ to 0.20 . Genotypic survival for the three strategies is summarized in Table 1.

\section{Identification of the optimal spatial configuration of refuges}

We used three kinds of criteria to identify the optimal spatial configuration of refuges and demonstrate the advantages of the strategy we recommend over the current $H D R$ strategy. First, we estimated allelic and density distributions at equilibrium in order to compare the efficiency of the different strategies to achieve sustainable pest control. The mean frequency of the

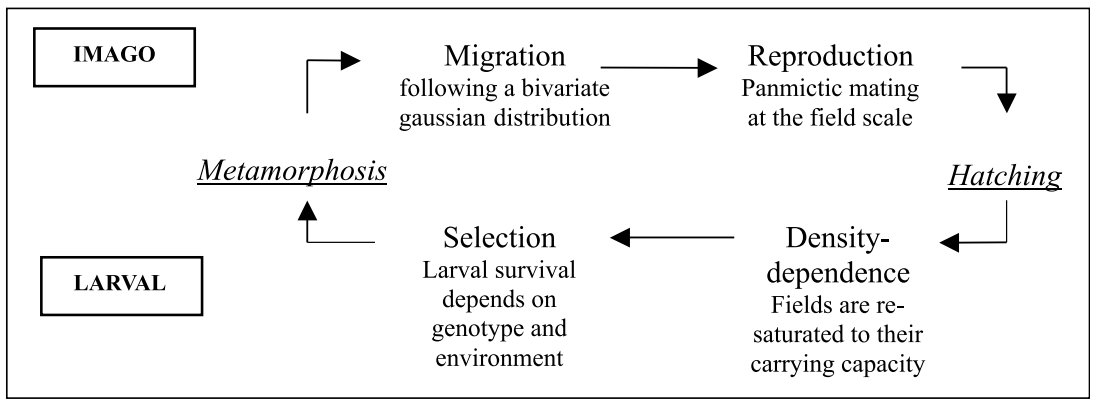

Fig. 2 Pest life cycle. 
Table 1 Survival rates (in \%) of the various larval genotypes in refuges and in $B t$ fields for various doses of toxin produced by transgenic plants. Survival rates correspond to the genotypic fitness.

\begin{tabular}{|c|c|c|c|c|}
\hline & \multicolumn{3}{|l|}{$B t$ fields } & \multirow[t]{2}{*}{ Refuges } \\
\hline & High dose & Middle dose & Low dose & \\
\hline SS & 0 & 20 & 40 & 100 \\
\hline RS & 2 & 21 & 40 & 97 \\
\hline $\mathrm{RR}$ & 85 & 85 & 85 & 85 \\
\hline
\end{tabular}

'High dose' strategy: $s=1.00, h_{s}=0.95, c=0.15, h_{c}=0.20$. 'Middle dose' strategy: $s=0.80, h_{s}=0.95, c=0.15, h_{c}=0.20$. 'Low dose' strategy: $s=0.60, h_{s}=0.95, c=0.15, h_{c}=0.20$.

resistance allele $f_{s}$, mean larval density $d_{s}$ over the whole cultivated region, mean larval density $d_{s, B t}$ in transgenic fields, and the mean larval density $d_{s, \text { ref }}$ in refuges were computed after selection. Secondly, we estimated the time to resistance $T_{50}$ (May \& Dobson, 1986) in order to compare the efficiency of the different strategies in delaying resistance evolution by a few years. $T_{50}$ was defined here as the number of generations required to reach a mean resistance allele frequency of $50 \%$. If we assume that $H$. virescens has three generations per year (Gianessi \& Carpenter, 1999), $T_{50}$ can be expressed in years. Thirdly, in order to gain insight into the economic interest of the different strategies, we calculated the total yield loss caused by pest damage occurring since the implementation of resistance management. We assumed that the yield loss on a given generation was directly proportional to pest density (see Comins, 1977b).

\section{Assessment of strategy robustness towards features of the biological system}

Although the $H$. virescens/cotton system is probably the best known for parameter estimates, some of the parameters - for instance the cost of resistance - are poorly known. Moreover, ecological and genetic features of the pest, along with habitat features, may vary through space and time. Consequently, we chose to assess the sensitivity of our strategy to three critical parameters. First, because costs of resistance are often difficult to detect (Cousteau et al., 2000), and because their decrease seems to be inevitable under the influence of fitness modifiers (McKenzie \& Purvis, 1984; Lenormand \& Raymond, 1998; Raymond et al., 1998), we studied the evolution of resistance for a range of low costs $(0 \leq c \leq 0.15)$. Secondly, because an increase in resistance allele frequency would be expected if conservative management strategies were not rapidly implemented, we investigated the evolution of resistance for a range of initial gene frequencies $\left(0.0015 \leq f_{s 0} \leq 0.015\right)$. Thirdly, as the model assumes a matrix of finite size with reflective boundaries, gene flow between fields may be influenced by the total size of the cultivated region.
Therefore, we studied the optimal spatial configuration of refuges for other matrix sizes $(n=10, n=30, n=40)$.

\section{Results}

\section{Optimal percentage and spatial configuration of refuge fields}

Extensive numerical simulations indicate that there is always an optimal percentage of refuge $\left(P_{\text {ref }}{ }^{*}\right)$, beyond which resistance does not evolve, and for which pest densities are minimal (Fig. 3; see also Lenormand $\delta$ Raymond, 1998). If the percentage of refuge is $<P_{\text {ref }} *$, then resistance is rapidly fixed and pests are numerous in both transgenic and refuge fields (Table 2). If the percentage of refuge is $>P_{\text {ref }}{ }^{*}$, then susceptible genotypes are fixed at equilibrium and pests are primarily found in refuge fields (Table 2). Consequently, pest density increases with the percentage of refuge. Therefore, use of a strategy in which the percentage refuge is equal to, or slightly higher than, $P_{\text {ref }}{ }^{*}$ is sensible as it should both prevent resistance and minimize pest densities.

We also investigated how the spatial configuration of the cultivated region affected the optimal percentage of refuge $P_{\text {ref }}{ }^{*}$. All else being equal, there is an optimal level

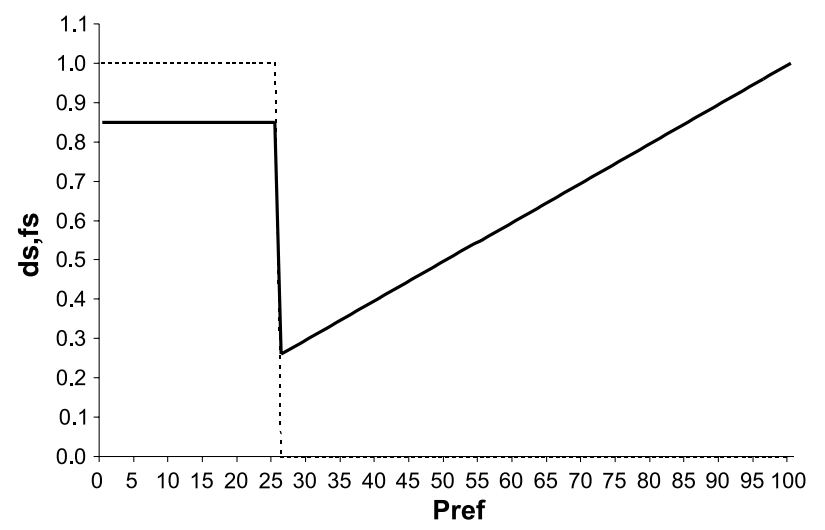

Fig. 3 Mean larval density at equilibrium ( $d_{s}$, solid lines) and the frequency of the resistance allele at equilibrium $\left(f_{s^{\prime}}\right.$ dotted lines $)$ as a function of the percentage of refuge $\left(P_{\text {ref }}\right)$. 'High dose' strategy: $s=1.00, h_{s}=0.95, c=0.15, h_{c}=0.20$. Refuges are aggregated into two strips.

Table 2 Mean larval density at equilibrium over the whole cultivated region $\left(d_{s}\right)$, in transgenic fields $\left(d_{s, B t}\right)$ and in refuges $\left(d_{s, \text { ref }}\right)$ as a function of the percentage of refuge $\left(P_{\text {ref }}\right)$. Parameters are the same as for Fig. 3.

\begin{tabular}{lccccc}
\hline$P_{\text {ref }}$ & $6 \%$ & $16 \%$ & $P_{\text {ref }}{ }^{*}=26 \%$ & $36 \%$ & $46 \%$ \\
\hline$d_{s}$ & 0.85 & 0.85 & 0.26 & 0.36 & 0.46 \\
$d_{s, B t}$ & 0.85 & 0.85 & $\approx 0$ & $\approx 0$ & $\approx 0$ \\
$d_{s, \text { ref }}$ & 0.85 & 0.85 & 1.00 & 1.00 & 1.00 \\
\hline
\end{tabular}


Table 3 Effect of the spatial configuration of refuges on the optimal percentage of refuge $\left(P_{\mathrm{ref}^{*}}\right)$ and on mean larval density at equilibrium over the whole cultivated region $\left(d_{s}\right)$. Results for the random distribution are the mean values of 20 simulations.

\begin{tabular}{ccccccccc}
\hline \multicolumn{4}{c}{ Aggregated into strips } & \multicolumn{4}{c}{ Random } & Uniform \\
\cline { 2 - 6 } & $A_{g}=1$ & $A_{g}=2$ & $A_{g}=3$ & $A_{g}=4$ & $A_{g}=5$ & & \\
\hline$P_{\text {ref }^{*}}$ & $58 \%$ & $26 \%$ & $35 \%$ & $40 \%$ & $41 \%$ & $41 \%$ & $42 \%$ \\
$d_{s}$ & 0.58 & 0.26 & 0.35 & 0.40 & 0.41 & 0.41 & 0.42 \\
\hline
\end{tabular}

'High dose' strategy: $s=1.00, h_{s}=0.95, c=0.15, h_{c}=0.20$.

of aggregation of refuge fields $A_{g}{ }^{*}$ that minimizes both the percentage of refuge required to prevent the evolution of resistance and associated pest density at equilibrium (Table 3). Thus, a percentage $P_{\text {ref }}{ }^{*}$ of refuge fields aggregated in $A_{g}{ }^{*}$ strips constitutes an optimal resistance management strategy, because it permits the sustainable control of pests with a minimal refuge area. Under the set of ecological and genetic parameters employed here for $H$. virescens/cotton, the strategy $\left(P_{\text {ref }}{ }^{*}=26 \%, A_{g}{ }^{*}=2\right)$ is the optimal strategy.

Finally, we compared the total yield loss caused by pest damage employing our predicted optimal strategy $\left(P_{\text {ref }}{ }^{*}=26 \%\right.$ and $\left.A_{g}{ }^{*}=2\right)$ and the strategy currently advised by the USEPA, i.e. 5\% unsprayed external refuges (USEPA, 2001). If refuge fields represent only $5 \%$ of the cultivated area, then pest density experiences a fast increase because of resistance evolution, whatever the distribution of refuges. When refuges are randomly distributed, pest density reaches its maximal density after 4 years (Fig. 4a). In contrast, with the strategy derived in the present study, pest density remains low and stable $\left(d_{s}=0.26\right.$, see Table 3 and Fig. 4a). As a consequence, total yield loss of the $5 \%$ random-distributed refuges strategy exceeds our optimal strategy after only 2.5 years (Fig. 4b). It is striking that differences in the respective performances appear so quickly.

\section{Impact of toxin dose on the optimal percentage of refuge}

We also investigated how the optimal percentage of refuge $P_{\text {ref }}{ }^{*}$ changed with the amount of toxin produced by transgenic plants. For the set of parameters chosen and for a given configuration of refuges, simulations show that $P_{\text {ref }}{ }^{*}$ increases with toxin dose (Table 4). This result is not surprising: the more advantageous resistance in transgenic fields, the higher the percentage of refuge fields required to counterbalance selection for the resistance allele. Moreover, simulations show that the higher the dose of toxin, the lower is the density of pests in transgenic fields (Table 4). This illustrates the trade-off between the efficacy of pest control and the area over which control can occur without resistance (Lenormand \& Raymond, 1998). Thus, the high toxicity of Bt proteins
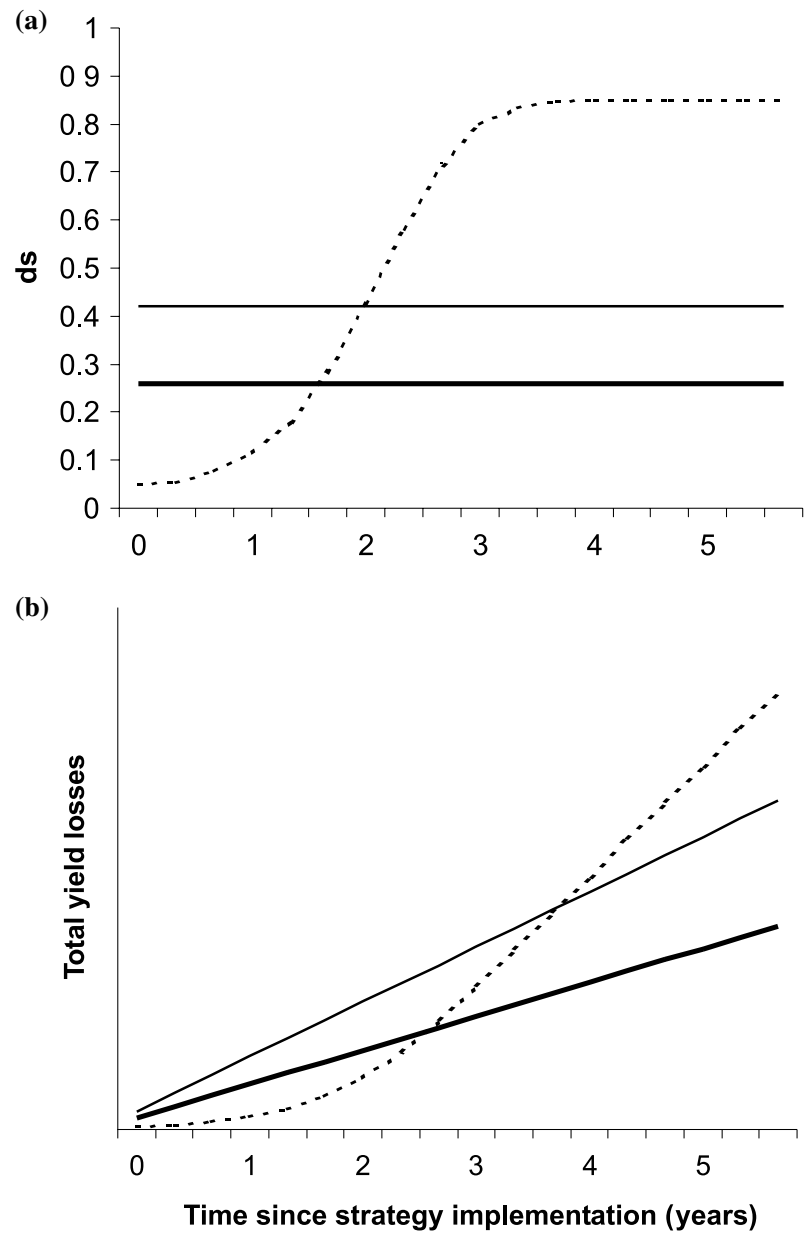

Fig. 4 Comparison of strategies under the criterion of cumulated yield losses. Dotted line: currently implemented strategy, i.e. 'highdose' of toxin, low percentage of refuge $\left(P_{\text {ref }}=5 \%\right)$ and no regional aggregation (we assumed that the lack of regional aggregation could be approximated by a random distribution and the line is based on the mean of 20 simulations). Solid lines: sustainable resistance management strategies suggested in this study, i.e 'high-dose' strategy with $P_{\text {ref }}=P_{\text {ref }}{ }^{*}=26 \%$ and $A_{g}=A_{g}{ }^{*}=2$ (thick line) or 'low-dose' strategy with $P_{\text {ref }}=P_{\text {ref }}^{*}=3 \%$ (thin line). (a) Mean larval density at equilibrium $\left(d_{s}\right)$ as a function of time. (b) Total yield losses caused by pest damage since implementation. As we assumed that yield losses for a given generation are directly proportional to larval density, these three lines correspond to the three lines of (a) cumulated over time.

and the high doses usually employed provide greater control of the pest in transgenic fields, but at the cost of larger refuges. It is noteworthy that under the criterion of cumulated yield losses, a low dose applied with $P_{\text {ref }}=P_{\text {ref }}{ }^{*}=3 \%$ (Fig. 4a) turns out to be more advantageous than the currently implemented HDR strategy within only 4 years (Fig. 4b). It is also noteworthy that for this very low percentage of refuge, the spatial configuration of refuge fields has no impact on the 
Table 4 Effect of toxin dose on the optimal percentage of refuge $\left(P_{\text {ref }^{*}}\right)$ and on mean larval density at equilibrium over the whole cultivated region, in transgenic fields and in refuges (respectively $d_{s^{\prime}}$ $d_{s, B t}$ and $\left.d_{s, \text { ref }}\right)$ for the optimal refuge $\left(P_{\text {ref }}{ }^{*}\right) \cdot h_{s}=0.95, c=0.15$, $h_{c}=0.20$. Refuges are aggregated into two strips.

\begin{tabular}{lrlcl}
\hline & $P_{\text {ref }^{*}}$ & $d_{s}$ & $d_{s, B t}$ & $d_{s, \text { ref }}$ \\
\hline High dose & $26 \%$ & 0.26 & $\approx 0$ & 1.00 \\
Middle dose & $21 \%$ & 0.37 & 0.20 & 1.00 \\
Low dose & $3 \%$ & 0.42 & 0.40 & 1.00 \\
\hline
\end{tabular}

evolution of resistance (hence $d_{s}=0.42$ whatever the spatial configuration, see Table 4).

\section{Robustness of the strategy to features of the biological system}

As expected, the greater the reduction in the cost of resistance, the less time it takes for resistance to evolve (Fig. 5a). If the cost of resistance is zero, the frequency of the resistance allele reaches $50 \%$ within only 10 years (Fig. 5a). Importantly however, regardless of the decrease in the cost of resistance, $T_{50}$ is maximal at $P_{\text {ref }}$ * (Fig. 5b) and $A_{g}{ }^{*}$ (Fig. 5c). Hence, the spatial structure parameters optimized for a system with cost to resistance remains optimal even if the cost experiences a decrease under the selection of fitness modifiers.

In contrast to costs of resistance, increasing the initial frequency of the resistance allele does have an effect on the optimal refuge level. For instance, increasing the initial frequency of the resistance allele from $f_{s o}=0.0015$ to $f_{s o}=0.015$ imposes an increase of $26-36 \%$ in $P_{\text {ref }}{ }^{*}$.
This sensitivity of $P_{\text {ref }}$ * to initial conditions is the result of marginal under-dominance, i.e. the lower mean fitness of heterozygotes across the environment than both homozygotes (Fig. 6a). Indeed, assuming panmixis over the whole cultivated region, it can be shown analytically that the system has two locally stable equilibria in the interval of marginal under-dominance, and that evolution towards one equilibrium or the other depends on initial conditions. For a given initial frequency of the resistance allele, its frequency at equilibrium is unity below the threshold $P_{\text {ref }}{ }^{*}$, whereas above $P_{\text {ref }}{ }^{*}$, it equals 0 (Fig. 6b).

Finally, we find that the optimal spatial structure of the agro-system is very similar in a $400-\mathrm{km}^{2}$ cultivated region compared with a $6400-\mathrm{km}^{2}$ cultivated region (Table 5). The optimal distribution is thus clearly a biological property of the crop/pest system rather than a modelling artefact.

\section{Discussion}

As long as there are costs to resistance, our simulations show that there is a percentage of refuge $P_{\text {ref }}{ }^{*}$ that both minimizes pest densities, thereby increasing short-term benefits, and prevents resistance, thereby allowing $B t$ plants to remain beneficial in the long term. Therefore, setting the percentage refuge to $P_{\text {ref }}{ }^{*}$, or slightly higher than $P_{\text {ref }}{ }^{*}$, is a sensible strategy to achieve sustainable pest control. Our simulations also show that the percentage of costly refuges $P_{\text {ref }}$ * can be reduced by lowering the amount of toxin produced by $B t$ plants and, more interestingly, through intermediate levels of aggregation of refuge fields. Thus, according to our results, the two (a)

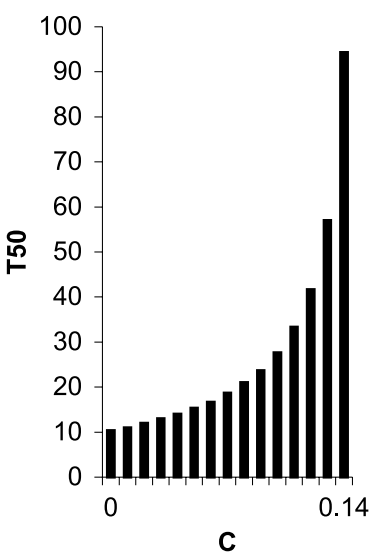

(b)

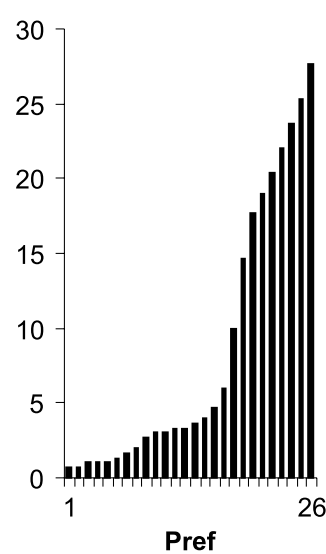

(c)

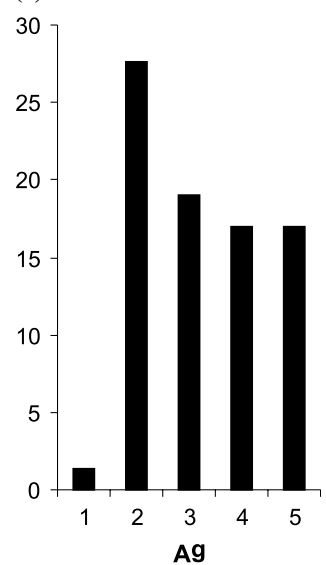

Fig. 5 Assessment of strategy robustness to a decrease in the cost of resistance. Genetic parameters are the same as for Fig. 3, except for the cost of resistance. (a) Time to resistance $\left(T_{50}\right)$ as a function of the cost of resistance $(c)$. The percentage of refuge and the level of aggregation are fixed at optimal levels $\left(P_{\mathrm{ref}}{ }^{*}=26 \%, A_{g}{ }^{*}=2\right)$ when $c=0.15$. As a consequence, time to resistance $\left(T_{50}\right)$ tends towards infinity if the cost of resistance (c) tends towards 0.15 . (b) Time to $50 \%$ resistance $\left(T_{50}\right)$ as a function of the percentage of refuge $\left(P_{\text {ref }}\right)$. The level of aggregation is fixed at the optimal level $A_{g}{ }^{*}=2$ and the cost of resistance to $c=0.10$. (c) Time to $50 \%$ resistance ( $T_{50}$ ) as a function of the level of aggregation of refuges $\left(A_{g}\right)$. The percentage of refuge is fixed to the optimal level $P_{\text {ref }}{ }^{*}=26 \%$ and the cost of resistance to $c=0.10$. 
(a)

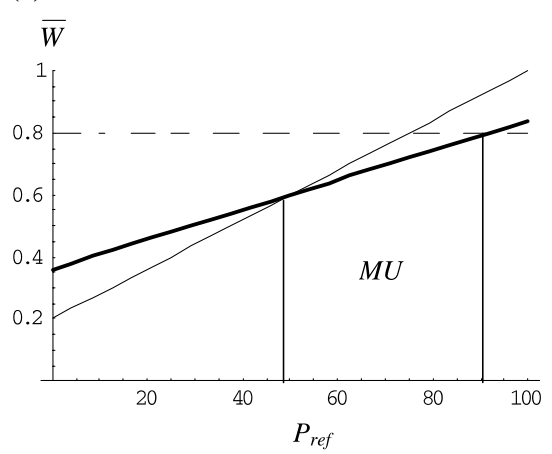

(b)

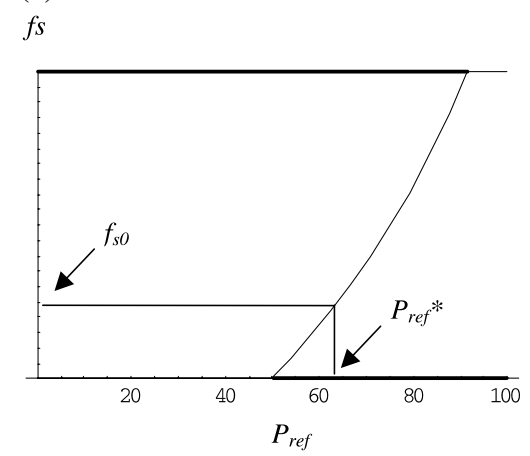

Fig. 6 Marginal under-dominance and dependence on initial conditions of allele frequencies at equilibrium. We consider here a panmictic model with a nontoxic habitat (refuge), accounting for a percentage $P_{\text {ref }}$ of the total planted area, and a toxic habitat. (a) Mean genotypic fitness across the environment $(\bar{W})$ as a function of the percentage of refuge $\left(P_{\text {ref }}\right)$. Depending on the set of genetic parameters chosen and on the percentage of refuge, heterozygotes $R S$ (thick line) may have a lower mean fitness than susceptible homozygotes $S S$ (thin line) and resistant homozygotes $R R$ (dashed line). This is marginal under-dominance $(M U)$. (b) Resistance allele frequency at equilibrium $\left(f_{s}\right)$ as a function of the percentage of refuge $\left(P_{\text {ref }}\right)$. The analytical study of resistance allele frequency at equilibrium $f_{s}$ shows that in the interval of marginal underdominance, an unstable equilibrium (thin line) separates two stable equilibria (thick line) (C. Vacher, unpublished data). Thus, the allele frequency $f_{s}$ at equilibrium depends on the initial allele frequency $f_{s o}$. The percentage of refuge $P_{\text {ref }}{ }^{*}$ above which the frequency of the resistance allele remains at zero is given by the intersection between $f_{\text {so }}$ and the unstable equilibrium.

Table 5 Effect of matrix size on the optimal percentage of refuge $\left(P_{\text {ref }}^{*}\right)$ and on the optimal level of aggregation $\left(A_{g}^{*}\right)$. The cultivated area equals $(d N)^{2}$. The optimal distance between refuge strips $\left(d_{\text {strip }}{ }^{*}\right)$ equals $d(N-1) / \mathrm{A}_{g}{ }^{*}$. 'High dose' strategy: $s=1.00, h_{s}=0.95, c=$ $0.15, h_{c}=0.20$.

\begin{tabular}{llllc}
\hline & Area $\left(\mathrm{km}^{2}\right)$ & $P_{\text {ref }}{ }^{*}(\%)$ & $A_{g}{ }^{*}$ & $d_{\text {strip }}{ }^{*}\left(\mathrm{~km}^{2}\right)$ \\
\hline$n=10$ & 400 & 27 & 1 & - \\
$n=20$ & 1600 & 26 & 2 & 19.0 \\
$n=30$ & 3600 & 26 & 3 & 19.3 \\
$n=40$ & 6400 & 26 & 4 & 19.5 \\
\hline
\end{tabular}

underlying principles of the HDR strategy - high toxin dose and refuge fields in close proximity to $B t$ plants - are not optimal if the goal of resistance management is to prevent pest resistance rather than just to slow its evolution.

\section{Evolutionary processes underlying the effect of environmental spatial structure}

The model presented here deals with the frequency evolution of a locally favoured (resistance) allele in an environment subdivided into two habitat types (transgenic crops and refuges). Theoretical models developed on this issue have shown that the evolution of gene frequencies depends on the relative size of each habitat type, on the strength of selection pressures in each habitat type and on the intensity of gene flow between habitats. Conditions which favour the appearance of clines in gene frequency (i.e. local adaptation) include strong positive selection in the favourable habitat type, strong negative selective selection in the unfavourable habitat type and a coarse-grained environment (Haldane, 1948; Slatkin, 1973; Nagylaki, 1975). Under the set of parameters chosen for $H$. virescens/cotton, these conditions are not met. Therefore, resistance evolution in our model is not a local adaptation process (but see Lenormand \& Raymond, 1998).

Our simulations show that the resistance allele frequency at equilibrium is uniform across habitats: it is equal to unity if the percentage of unfavourable habitats (refuges) is below the threshold $P_{\text {ref }}{ }^{*}$ and to zero otherwise. Because we assumed space-limited migration instead of making the simplifying assumption of global panmixis, an interesting property of our model is that the spatial aggregation of unfavourable habitats has a strong impact on the threshold $P_{\text {ref }}{ }^{*}: P_{\text {ref }}$ * is minimal for intermediate levels of aggregation of unfavourable habitats $A_{g}{ }^{*}$. This effect may be explained by two antagonistic effects of gene flow between habitats on resistance evolution (Comins, 1977a). On the one hand, gene flow from refuges towards transgenic crops counteracts changes in allele frequencies caused by selection in transgenic habitats, and tends to cause the loss of the resistance allele ('gene swamping' effect, Lenormand, 2002). On the other hand, gene flow from transgenic crops towards refuges tends to increase the frequency of the resistance gene in refuges and therefore decrease their efficiency at counteracting resistance. The first process may account for the observed decrease in $P_{\text {ref }}$ * with gene flow (i.e. increase with refuge aggregation), whereas the second process may account for its observed increase with gene flow (i.e. decrease with refuge aggregation). 


\section{Sustainable control of pests or HDR strategy?}

Under the set of genetic and ecological parameters chosen for $H$. virescens/cotton, the optimal percentage of refuge is $c .25 \%$. This value is much higher than the $5 \%$ area of untreated refuges currently implemented by cotton growers (USEPA, 2001). The very low percentage of refuge recommended for $B t$ cotton is a matter of debate (Neppl, 2000). For other crops, the percentage refuge recommended by the Environmental Protection Agency is higher and closer to our estimation for halting resistance in $H$. virescens: it ranges from $20 \%$ in $B t$ potatoes to $50 \%$ in $B t$ corn (when corn is cultivated in areas where $B t$ cotton is also grown) (Neppl, 2000). Thus, the $25 \%$ refuge we recommend might be acceptable to farmers. Below we develop three points to demonstrate the advantages of our strategy over the $H D R$ strategy within the context of a sustainable agriculture development.

First and foremost, employing a simple loss function, we showed that the yield losses experienced under the $H D R$ strategy, although smaller during the first couple of years, rapidly overwhelm the yield losses experienced under our optimal strategy. Resistance to $B t$ toxins under the $H D R$ strategy will not only be costly to farmers and industries relying on transgenic technologies, but also to farmers developing biological agriculture because $B t$ toxin sprays are their main means of pest control (Gould, 1998). Resistance to $B t$ toxins under the $H D R$ strategy will also lead to the replacement of transgenic insectresistant varieties - presumably safe for the environment and health, and economically advantageous over conventional varieties - by other varieties and other technologies for which risks remain to be assessed.

Secondly, our simulations suggest that the optimal percentage of refuge can be reduced by using Bt cotton varieties that produce less toxin than is currently the case. For instance, the dose of toxin ingested by arthropod pests could be modified by placing the resistance gene under the control of a specific promoter (e.g. Carozzi et al., 1992), limiting toxin gene expression to the most vulnerable plant parts or to the point in pest phenology when it is most needed (Gould, 1998). Less toxic proteins, such as protease inhibitors (Johnson et al., 1989; McManus et al., 1994), could also be used. Although lowering the toxin dose would lead to an immediate decrease in pest control efficacy in transgenic fields, it may still reduce the local losses on a medium-term basis when compared with an $H D R$ strategy with insufficiently sized and/or insufficiently aggregated refuges.

Thirdly and as noted by Caprio (2001), our model suggests that the habitat should not be too fine-grained for optimal resistance management. In the case of $H$. virescens and high-toxin $B t$ crops, the optimal refuge distribution is predicted to be aggregated in 19-km-wide strips. The implementation of our findings would require the management of resistance on a regional scale (Peck et al., 1999), an important benefit being regional economic viability and a smaller financial burden on individual farmers. Moreover, aggregation strategies have an advantage over the random or uniform deployment of refuges in that they limit the risk of contamination during harvesting. The segregation of transgenic and nontransgenic markets, which is presently considered the most viable approach for future European agricultural policy (Chevassus-au-Louis, 2001), would thus be facilitated by such a strategy (Nelson et al., 1999).

\section{Robustness and generalization to other pests}

Risks regarding errors in the estimation of $P_{\text {ref }}$ * are asymmetric: an underestimation would lead to a dramatic increase in yield losses over Bt fields when resistance starts to evolve, whereas an overestimation would lead to yield losses corresponding to a slight increase in pest density over refuge fields. Adopting a percentage of refuge slightly greater than $P_{\text {ref }}{ }^{*}$ thus seems wise. One of the assumptions of the model on pest life cycles - i.e. the re-saturation of fields at carrying capacity and at each generation - favours resistance evolution because pest densities are prevented from reaching very low levels in transgenic fields (Lenormand, 2002). In other words, our calculations should tend to overestimate $P_{\text {ref }}$.

An important aspect of the resistance management strategy proposed here is its robustness to a decrease in fitness cost under the influence of fitness modifiers. Although resistance evolution cannot be prevented when there are no costs, it may be substantially delayed if a $\left(P_{\text {ref }}{ }^{*}, A_{g}{ }^{*}\right)$ configuration is adopted. This result has two important consequences. First, the optimal structure of the agro-ecosystem identified here $\left(P_{\text {ref }}{ }^{*}, A_{g}{ }^{*}\right)$ can be employed without the estimation of a fitness cost. Secondly, because fitness modifier alleles will not be strongly selected as long as the frequency of the resistance allele remains low (Lenormand \& Raymond, 1998), the optimal structure $\left(P_{\mathrm{ref}}{ }^{*}, A_{g}{ }^{*}\right)$ is more likely to delay the selection of modifiers, which will tend to delay the onset of resistance even further.

Three important assumptions of the model must be verified to assess the robustness of our results concerning reductions in toxin dose. First and foremost, genotype toxin dose-mortality curves must be accurately estimated for insect larvae. Indeed, we assumed that the functional recessivity of resistance $\left(h_{s}\right)$ is not affected by the amount of toxin produced by transgenic plants. However, a strong decrease in the functional recessivity of resistance with toxin dose (Tabashnik \& Croft, 1982; Georghiou \& Taylor, 1986; Bourguet et al., 2000b) could overcome the effect of a reduction in toxin dose and even lead to an increase in the optimal percentage of refuge. Secondly, knowledge about the form of dominance will determine if one needs to be concerned about initial frequencies of resistance alleles. For marginal under-dominance, estimations of $B t$ resistance can be crucial in deriving the 
optimal conditions, whereas in marginal overdominance, this is not a concern. Thirdly, we assumed that the crop is attacked by one herbivore species only and caution is thus required if crops serve as hosts to several herbivore species differing in susceptibility to the toxin. For instance, Bt cotton is highly toxic to tobacco budworm (H. virescens) and pink bollworm (Pectinophora gossypiella), but only moderately toxic to cotton bollworm (Helicoverpa armigera) (Gianessi \& Carpenter, 1999; Neppl, 2000). A substantial reduction in toxin dose could therefore result in an increase in the cotton bollworm population.

Future studies should assess the optimal spatial structure for other crop/pest systems. We predict that transgenic fields should be (1) aggregated to a greater extent to combat insects with large dispersal distances, such as the European corn borer (Ostrinia nubilalis) (Bourguet et al., 2000a), an important pest of corn and (2) less clumped for insects with restricted movement, such as the Colorado potato beetle ( $L$. decemlineata) (Follet et al., 1996; Alyokhin \& Ferro, 1999b), a key pest of potatoes.

\section{Acknowledgments}

We thank Michel Raymond, Thomas Lenormand, Tony Ives, Art Weis and two anonymous reviewers for helpful comments. We acknowledge financial support from the French Ministry of Research (AIP 'Impact des OGM') and Education and the Centre National de la Recherche Scientifique (programme Jeunes Equipes).

\section{References}

Alstad, D.N. \& Andow, D.A. 1995. Managing the evolution of insect resistance to transgenic plants. Science 268: 1894-1896.

Alyokhin, A.V. \& Ferro, D.N. 1999a. Relative fitness of Colorado potato beetle (Coleoptera: Chrysomelidae) resistant and susceptible to the Bacillus thuringiensis Cry3A toxin. J. Econ. Entomol. 92: 512-515.

Alyokhin, A.V. \& Ferro, D.N. 1999b. Reproduction and dispersal of summer-generation Colorado potato beetle (Coleoptera: Chrysomelidae). J. Econ. Entomol. 28: 425-430.

Andersen, J.L. 1999. Letter to Bt Corn Registrants. Available at http://www.epa.gov/oppbppdl/biopesticides/otherdocs/ bt_corn_ltr.htm.

Bourguet, D., Bethenod, M.T., Pasteur, N. \& Viard, F. 2000a. Gene flow in the European corn borer Ostrinia nubilalis: implications for the sustainability of transgenic insecticidal maize. Proc. R. Soc. Lond. B 267: 117-122.

Bourguet, D., Génissel, A. \& Raymond, M. 2000b. Insecticide resistance and dominance levels. J. Econ. Entomol. 93: 15851593.

Caprio, M.A. 1998. Evaluating resistance management strategies for multiple toxins in the presence of external refuges. J. Econ. Entomol. 91: 1021-1031.

Caprio, M.A. 2001. Source-sink dynamics between transgenic and non-transgenic habitats and their role in the evolution of resistance. J. Econ. Entomol. 94: 698-705.
Carozzi, N.B., Warren, G.W., Desai, N., Jayne, S.M., Lotstein, R., Rice, D.A., Evola, S. \& Koziel, M.G. 1992. Expression of a chimeric CaMV 35S Bacillus thuringiensis insecticidal protein gene in transgenic tobacco. Plant Mol Biol. 20: 539-548.

Carrière, Y. \& Tabashnik, B.E. 2001. Reversing insect adaptation to transgenic insecticidal plants. Proc. R. Soc. Lond. B. 268: $1475-1480$.

Chevassus-au-Louis, B. 2001. OGM et Agriculture: Options pour L'Action Publique. Commissariat Général du Plan, Paris.

Comins, H.N. 1977a. The development of insecticide resistance in the presence of migration. J. Theor. Biol. 64: 177-197.

Comins, H.N. 1977b. The management of pesticide resistance. J. Theor. Biol. 65: 399-420.

Cousteau, C., Chevillon, C. \& ffrench-Constant, R. 2000. Resistance to xenobiotics and parasites: can we count the cost? TREE 15: 378-383.

Daniels, R.E. \& Sheail, J. 1999. 'Genetic pollution: concepts, concerns and transgenic crops' Symposium Proceedings 72. Gene Flow and Agriculture, Relevance for Transgenic Crops, pp. 65-72.

Follett, P.A., Cantelo, G.W. \& Roderick, G.K. 1996. Local dispersal of overwintered Colorado potato beetle (Chrysomelidae: Coloptera) determined by mark and recapture. Env. Entomol. 25: 1304-1311.

Gahan, L.J., Gould, F. \& Heckel, D.G. 2001. Identification of a gene associated with Bt resistance in Heliothis virescens. Science 293: 857-860.

Georghiou, G.P. \& Taylor, C.E. 1986. Factors influencing the evolution of resistance. In: Pesticide Resistance: Strategies and Tactics for Management, pp. 157-169. National Academy Press, Washington, USA.

Gianessi, L.P. \& Carpenter, J.E. 1999. Agricultural Biotechnology: Insect Control. Benefits. National Center for Food and Agriculture Policy, Washington, USA.

Gould, F. 1998. Sustainability of transgenic insecticidal cultivars: integrating pest genetics and ecology. Annu. Rev. Entomol. 43: 701-726.

Gould, F., Anderson, A., Jones, A., Sumerford, D., Heckel, D.G., Lopez, J., Micinksy, S., Leonard, R. \& Laster, M. 1997. Initial frequency of alleles for resistance to Bacillus thuringiensis toxins in field populations of Heliothis virescens. Proc. Natl. Acad. Sci. USA 94: 3519-3523.

Gould, F., Anderson, A., Reynolds, A., Bumgarner, L. \& Moar, W. 1995. Selection and genetic analysis of a Heliothis virescens (Lepidoptera: Noctuidae) strain with high levels of resistance to Bacillus thuringiensis toxins. J. Econ. Entomol. 88: 1545-1559.

Groeters, F.R., Tabashnik, B.E., Finson, N. \& Johnson, M.W. 1994. Fitness costs of resistance to Bacillus thuringiensis in the diamondback moth (Plutella xylostella). Evolution 48: 197-201.

Haldane, J.B. 1948. The theory of a cline. J. Genet. 48: 277-284.

ILSI. 1998. An Evaluation of Insect Resistance Management in Bt Field Corn: a Science-Based Framework for Risk Assessment and Risk Management. International Life Sciences Institute, ILSI Press, Washington, USA.

Ives, A.R. 1996. Evolution of insect resistance to Bacillus thuringiensis-transformed plants. Science 273: 1412-1413.

Johnson, R., Narvaez, J., An, G. \& Ryan, C.A. 1989. Expression of protease inhibitor I and II in transgenic tobacco plants: effects on natural defense against Manduca sexta larvae. Proc. Natl. Acad. Sci. USA 86: 9871-9875.

Korman, A.K., Mallet, J., Goodenough, J.L., Graves, J.G., Hayes, J.L., Hendricks, D.E., Luttreel, R., Pair, S.D. \& Wall, M. 1993. 
Population structure of Heliothis virescens (Lepidoptera: Noctuidae): an estimate of gene flow. Ann. Entomol. Soc. Am. 86: $182-188$.

Lenormand, T. 2002. Gene flow and the limits to natural selection. TREE 17: 183-189.

Lenormand, T. \& Raymond, M. 1998. Resistance management: the stable zone strategy. Proc. R. Soc. Lond. B. 265: 1985-1990.

Mallet, J. \& Porter, P. 1992. Preventing insect adaptation to insect-resistant crops: are seed mixtures or refugia the best strategy? Proc. R. Soc. Lond. B. 250: 165-169.

May, R.E. \& Dobson, A.P. 1986. Population dynamics and the rate of evolution of pesticide resistance. In: Pesticide Resistance: Strategies and Tactics for Management, pp. 171-193. National Academy Press, Washington, USA.

McKenzie, J.A. \& Purvis, A. 1984. Chromosomal localization of fitness modifiers of diazon resistance genotypes of Lucilia cuprina. Heredity 53: 625-634.

McManus, M.T., White, D.W.R. \& McGregor, P.G. 1994. Accumulation of a chymotrypsin inhibitor in transgenic tobacco can affect the growth of insect pests. Transgenic Res. 3: $50-58$.

Nagylaki, T. 1975. Conditions for the existence of clines. Genetics 80: 595-615.

Nelson, G.C., Josling, T., Bullock, D., Unnevehr, L., Rosegrant, M. \& Hill, L. 1999. The Economics and Politics of Genetically Modified Organisms in Agriculture: Implications for WTO 2000. Bulletin 809. University of Illinois at Urbana-Champaign, Illinois, USA.

Neppl, C.C. 2000. Management of Resistance to Bacillus Thuringiensis toxins, The Environmental Studies Program. University of Chicago. Available at http://camillapede.tripod.com/bapaper.html.

Onstad, D.W. \& Gould, F. 1998. Modeling the dynamics of adaptation to transgenic maize by European corn borer (Lepidoptera: Pyralidae). J. Econ. Entomol. 91: 585-593.

Peck, S.L., Gould, F. \& Ellner, S.P. 1999. Spread of resistance in spatially extended regions of transgenic cotton: implications for management of Heliothis virescens (Lepidoptera: Noctuidae). J. Econ. Entomol. 92: 1-16.

Rausher, M.D. 2000. Co-evolution and plant resistance to natural enemies. Nature 411: 857-863.

Raymond, M., Chevillon, C., Guillemaud, T., Lenormand, T. $\delta$ Pasteur, N. 1998. An overview of the evolution of overproduced esterases in the mosquito Culex pipiens. Phil. Trans. $R$. Soc. Lond. 353: 1707-1711.

Roush, R.T. 1998. Two-toxin strategies for management of insecticidal trangenic crops: can pyramiding succeed where pesticide mixtures have not?. Phil. Trans. R. Soc. Lond. B 353: 1777-1786.

Shelton, A.M., Tang, J.D., Roush, R.T., Metz, T.D. \& Earle, E.D. 2000. Field tests on managing resistance to Bt-engineered plants. Nature Biotechnol. 18: 339-342.

Slatkin, M. 1973. Gene flow and selection in a cline. Genetics $\mathbf{7 5}$ : 733-756.

Tabashnik, B.E. 1994. Delaying insect adaptation to transgenic plants: seed mixtures and refugia reconsidered. Proc. $R$. Soc. Lond. B 255: 7-12.

Tabashnik, B.E. \& Croft, B.A. 1982. Managing pesticide resistance in crop-arthropod complexes: interactions between biological and operational factors. Environ. Entomol. 11: 1137-1 144.

Tang, J.D., Collins, H.L., Metz, T.D., Earle, E.D., Zhao, J.Z., Roush, R.T. \& Shelton, A.M. 2001. Greenhouse tests on resistance management of Bt transgenic plants using refuge strategies. J. Econ. Entomol. 94: 241-247.

USEPA, 2001. Bt cotton refuge requirements for the 2001 growing season. Available at http://www.epa.gov/oppbppdl/ biopesticides/otherdocs/bt_cotton_refuge_2001.htm.

Wolfenbarger, L.L. \& Phifer, P.R. 2000. The ecological risks and benefits of genetically engineered plants. Science 290: 20882093.

Received 27 September 2002; revised 10 February 2003; accepted 18 March 2003 